\title{
Culturas populares na universidade: uma proposta de educação decolonial
}

\author{
Pedro Rodolpho Jungers Abib* \\ Lucas Gesteira Ramos da Silva*
}

\section{Introdução}

Busca-se neste artigo reunir elementos para uma reflexão sobre práticas educacionais baseadas na experiência e na oralidade, que aproximam a formação acadêmica de cursos de graduaçáo e pós-graduação com a prática e o conhecimento de comunidades tradicionais vinculadas às ancestralidades africanas e indígenas, como processo de reconhecimento e valorização desses saberes e práticas num caminho para a formação humana no ensino superior de nosso país.

Assim, gostaríamos de apresentar aqui uma experiência já em prática há vários anos na Universidade Federal da Bahia (UFBA), que se caracteriza como uma nova concepção de disciplina acadêmica, pois se diferencia dos componentes curriculares convencionais por ser um espaço de diálogo entre os saberes comunitários tradicionais e os saberes acadêmico-científicos. Estamos falando da Ação Curricular em Comunidade e em Sociedade (ACCS).

* Professor da Universidade Federal da Bahia (UFBA); Doutor em Ciências Sociais aplicadas à Educação pela Universidade Estadual de Campinas (UNICAMP); Coordenador do Grupo de Pesquisa Griô: Culturas Populares, Ancestralidades e Educação, ligado à Facul-dade de Educação da UFBA; sambista e capoeirista angoleiro discípulo do mestre João Pequeno de Pastinha. E-mail: pedra-bib@gmail.com.

** Capoeirista Angoleiro, Educador Popular, Graduado no Bacharelado Interdisciplinar em Artes pela Universidade Federal da Bahia (UFBA), mestrando do Programa de Pós Graduação em Educação e Contemporaneidade pela Universidade do Estado da Bahia (UNEB). E-mail: lucasgesteira95@gmail. com. 
Dentre as várias modalidades de ACCS que integram essa iniciativa - que abrange diversas áreas de conhecimento na UFBA -, foi criada pela Faculdade de Educação uma ACCS específica, denominada "Saberes e Fazeres das Culturas Populares na Educação", que se articula a partir de encontros entre os estudantes da universidade e os sujeitos protagonistas desses saberes e fazeres, tanto no espaço acadêmico como em diversos territórios de identidade do estado da Bahia, onde acontecem trocas, experiências, vivências, compartilhamentos, aprendizados, interaçóes, celebraçóes, cooperaçóes, numa perspectiva de valorizaçáo da diversidade cultural, da ancestralidade, da tradição, da ritualidade, da memória, da oralidade, da solidariedade, e da construção coletiva dos saberes, buscando contribuir na formação de futuros profissionais mais humanizados e conscientes de sua identidade, sua cultura e seu papel social.

Pretendemos estabelecer aqui um diálogo com a literatura específica, sobretudo com os estudos culturais e o pensamento decolonial, estabelecendo alguns princípios que consideramos fundamentais para a compreensão de processos educacionais que valorizem o diálogo entre saberes e que respeitem a memória e a ancestralidade dos povos originários e dos povos de descendência africana, sequestrados de seus territórios para se tornarem escravos no Brasil, como fundamentais para uma educação libertadora e decolonial.

Analisaremos então essa experiência acadêmica, trazendo num primeiro momento uma descrição de suas práticas vivenciadas na universidade, bem como suas articulaçóes com as comunidades tradicionais do estado da Bahia, buscando um diálogo com os protagonistas dos saberes e fazeres das culturas populares - mestres, mestras, cantadores, violeiros, benzedeiras, cordelistas, mães de santo, garimpeiros, contadoras de histórias, ganhadeiras, capoeiristas, sambadeiras e sambadores, entres outros detentores desses fazeres e saberes, tão pouco valorizados no ambiente acadêmico.

Num segundo momento, traremos aqui os depoimentos de estudantes participantes dessas experiências, buscando refletir como essas vivências e práticas têm contribuído não somente para o seu processo de formação acadêmica, mas sobretudo para a sua formação humana de uma forma mais geral.

Tendo como base teórica os Estudos Culturais (Hall, 2009; Bhabha, 2009; Canclini, 2008, entre outros), o Pensamento Decolonial (Candal, 2010; Torres, 2007; Quijano, 2005; Walsh, 2005) e a própria experiência de um dos autores desse artigo no desenvolvimento de reflexóes sobre as culturas populares e a educação (Abib, 2005, 2015, 2019), buscamos dessa modo apresentar elementos que possam definir uma proposta de atuação no âmbito acadêmico a partir do diálogo com as experiências advindas dos saberes e fazeres tradicionais.

Esperamos, assim, compartilhar e socializar essa experiência que tem 
mobilizado os alunos de graduação da UFBA de todas as áreas do conhecimento, num processo de aproximação e valorização dos saberes populares tradicionais como imprescindíveis para sua formação profissional e dessa forma contribuir com a construçáo de uma nova maneira de se pensar a educação, não somente no âmbito acadêmico, como também em todos os níveis de ensino em nosso país. Esse artigo teve como colaboradora Rosevânia Machado, graduada em Biblioteconomia pela UFBA, que foi monitora dessa ACCS durante vários semestres.

\section{Ação Curricular em Comunidade e em Sociedade: uma experiência inovadora na UFBA}

Ação Curricular em Comunidade e em Sociedade (ACCS) é um componente curricular, modalidade disciplina, de cursos de graduação e de pós-graduação, criada no início da década de 2000, com carga horária entre 17 (dezessete) e 68 (sessenta e oito) horas semestrais, em que estudantes e professores da UFBA, em uma relação com diversos grupos da sociedade, desenvolvem açóes de extensão no âmbito da cultura, educação, criação, tecnologia e inovação, promovendo o intercâmbio, a reelaboração e a produção de saberes.

Segundo a Pró Reitoria de Extensão da UFBA,

[...] a ACCS deve ser desenvolvida numa perspectiva dialética e dialógica, participativa e compartilhada por intermédio de intervençóes em comunidades e grupos sociais, na busca de alternativas para o enfrentamento de problemáticas que emergem na realidade contemporânea. (Proext/UFBA, 2018).

A ACCS tem características comuns às demais disciplinas, quanto à criação, à oferta e à matrícula. Diferencia-se, entretanto, pela liberdade na escolha de temáticas, na definição de programas e na experimentação de procedimentos metodológicos, bem como pela possibilidade de assumir um caráter renovável. As ACCSs abrangem as diversas áreas de conhecimento cobertas pelos cursos de graduação e pós-graduação da UFBA, trabalhados, preferencialmente, de forma interdisciplinar e transdisciplinar. Por isso, sua realizaçáo plena supóe intensa cooperação entre docentes, discentes e grupos da comunidade e da sociedade.

A partir da abertura proporcionada por esse projeto gerido pela Pró Reitoria de Extensão da UFBA, propusemos a criação da ACCS "Saberes e Fazeres das Culturas Populares na Educação", oferecida pela Faculdade de Educação da 
UFBA, que tem como um dos principais objetivos: proporcionar as trocas e diálogos entre os saberes e fazeres provenientes da cultura popular e os saberes acadêmico-científicos, através da valorização da presença de mestres/mestras da cultura popular no ambiente acadêmico, e também do deslocamento dos alunos até os territórios de origem dessas manifestaçóes tradicionais populares.

A ACCS "Saberes e Fazeres das Culturas Populares na Educaçáo" se propõe a atuar nos mais diversos contextos sociais, articulando os saberes científicos e os saberes e fazeres provenientes do universo das culturas populares. A universidade ainda está um pouco distante dessa realidade, demonstrando certo estranhamento e até mesmo certo desprezo intelectual, em relação ao que é produzido pelos sujeitos detentores desses saberes populares e tradicionais. $\mathrm{O}$ constante trânsito entre os espaços acadêmicos e os territórios ligados à tradiçáo, por parte de estudantes, professores e pesquisadores de um lado, e de mestres e educadores da cultura popular de outro, é a tônica dessa ACCS.

A História Oral se torna uma referência importante para a metodologia dessa proposta, pois o contato com mestras e mestres e suas histórias permite nos levar para além do conhecimento de mais uma versáo do passado e a aprender algo sobre o presente, pois segundo Verena Alberti, “ a História Oral tem o grande mérito de permitir que os fenômenos subjetivos se tornem inteligíveis, capazes de incidir sobre a realidade" (Alberti, 2004, p. 9).

Ao utilizarmos a noção de "culturas populares" como central na abordagem proposta por essa ACCS, nos valemos de Homi Bhabha (2009), que afirma que toda uma produçáo contemporânea crítica sugere que é com aqueles que sofreram o sentenciamento da História - subjugação, dominação, diáspora, deslocamento - que aprendemos nossas liçóes mais duradouras da vida e pensamento. A experiência afetiva da marginalidade social, segundo o autor, transforma nossas estratégias críticas e nos força a encarar o conceito de cultura para além da canonização da ideia de estética, e lidar com a cultura como produção irregular e incompleta de sentido de valor, produzidas no ato de sobrevivência social.

Temos nos últimos anos (Abib, 2005, 2015, 2019), através de pesquisas, publicaçóes e açóes específicas nesse campo, nos esforçado para constituir elementos que possam definir melhor o que seria a noção de "culturas populares" que aqui utilizamos.

Nestor Garcia Canclini, por exemplo, nos ajuda a compreender um pouco mais sobre essa noçáo quando afirma que a "ampliação conceitual do termo 'popular' permite abranger formas de elaboração simbólica e movimentos sociais não deriváveis de seu lugar nas relaçôes de produção” (Canclini, 2008, p. 272).

Como afirma Stuart Hall, "definir conceitualmente o termo 'popular' é quase tão difícil quanto definir o termo 'cultura” (Hall, 2009, p. 233). O autor alega 
que juntar os dois termos pode tornar essa tarefa ainda mais difícil dado o caráter ambíguo das culturas populares, assim como também pontua Marilena Chauí, que aponta que a ambivalência presente nesse universo gera um tipo de atitude "capaz de resistência ao se conformar e conformismo ao resistir" (Chaúi, 1989, p. 124). O estudo sobre culturas populares na contemporaneidade, portanto, deve levar em consideração essa complexidade.

Stuart Hall entende a cultura popular enquanto terreno de tensóes e antagonismos, quando afirma que:

[...] o essencial em uma definição de cultura popular são as relações que colocam a 'cultura popular' em uma tensão contínua (de relacionamento, influência e antagonismo) com a cultura dominante. Trata-se de uma definição de cultura que se polariza em torno dessa dialética cultural. Observa o processo pelo qual as relações de domínio e subordinação são articuladas. Trata-se de um processo pelo qual algumas coisas são ativamente preferidas para que outras possam ser destronadas. (Hall, 2009, p. 241).

Essa compreensão trazida por Hall reforça o sentido e o conteúdo político que se articula em torno da noçâo de cultura popular. Em seu centro estão as relaçôes de poder mutáveis e irregulares que definem o campo da cultura, isto é, a luta cultural e suas múltiplas formas. Seu principal foco - em termos gramscianos - é a relação entre cultura e as questóes de hegemonia.

Ao discutirmos o tema: "cultura popular na contemporaneidade" em artigo anterior (Abib, 2015), afirmamos que não seria mais possível hoje em dia operar com a clássica divisão entre "cultura erudita", "cultura popular" e "cultura de massa" de forma tão simplificada como muito se fez. A imensa teia de articulaçóes em torno da noção de cultura não permitiriam mais essa classificação, visto que o trânsito de influências, arranjos e combinaçóes faz com que os mais variados campos de atuação cultural se interpenetrem o tempo todo e em todas as direçóes.

Insistimos aqui, portanto, na compreensáo sobre culturas populares e os processos educacionais que elas engendram como terreno de luta, onde memórias, tradiçóes, ancestralidades, espiritualidades e identidades são acionadas enquanto força motriz que demarca posiçóes e faz reverberar vozes, que buscam reconhecimento e autonomia diante da cultura hegemônica (Abib, 2019).

Ailton Krenak, importante liderança indígena brasileira e também intelectual autor de vários textos sobre a temática, afirma que a oralidade, como característica dos povos tradicionais, fortalece o sentido de pertencimento ao grupo e, assim como outras experiências compartilhadas, "vai integrando um sentido da vida, enriquecendo a experiência da vida de cada sujeito, mas, sobretudo, constituindo 
um sujeito coletivo" (Krenak, 2018), fator que, segundo ele, empodera as comunidades tradicionais para suas lutas por direitos e justiça.

O pensamento decolonial por sua vez, que tem se desenvolvido e se propagado por vários países afetados pelos processos de colonização, sobretudo na América Latina nos últimos anos, também nos ajuda na reflexão sobre a importância e a necessidade da defesa, da preservaçáo e da valorização do pensamento e das práticas tradicionais dos povos originários e dos povos descendentes de africanos e de como esses saberes provenientes da experiência desses, historicamente dominados e subjugados, podem se tornar uma referência epistêmica da maior importância nos processos educacionais pautados nesse viés.

O importante impacto que o pensamento decolonial tem exercido no debate sobre educação no Brasil nos últimos anos, conforme Oliveira e Candal (2010), coloca no centro da discussão a necessidade da construção de um projeto de emancipação epistêmica, que é nada mais do que a coexistência de diferentes epistêmes ou formas de produção de conhecimento entre intelectuais, tanto na academia, quanto nos movimentos sociais, colocando em evidência a questáo da geopolítica do conhecimento. Entende-se aqui geopolítica do conhecimento como a estratégia da modernidade europeia que afirmou suas teorias, seus conhecimentos e seus paradigmas como verdades universais e invisibilizou e silenciou os sujeitos que produzem conhecimentos "outros". Foi esse o processo que constituiu a modernidade, que náo pode ser entendida sem se tomar em conta os nexos com a herança colonial e as diferenças étnicas que o poder moderno/ colonial produziu.

O filósofo porto-riquenho Nelson Maldonado-Torres (2007), ao diferenciar os conceitos "colonialismo e colonialidade", afirma que a ideia de colonialismo está ligada ao poder econômico, militar, jurídico e político que uma nação exerce sobre outra. Por outro lado, a idéia de colonialidade é mais profunda e atinge as mentalidades dos povos colonizados. Segundo o autor, a colonialidade

[...] se mantém viva em textos didáticos, nos critérios para o bom trabalho acadêmico, na cultura, no sentido comum, na auto-imagem dos povos, nas aspiraçóes dos sujeitos e em muitos outros aspectos de nossa experiência moderna. Neste sentido, respiramos a colonialidade na modernidade cotidianamente. (Maldonado-Torres, 2007, p. 131).

O colonialismo, dessa forma, vai muito além de uma imposição política, militar, jurídica ou administrativa. Ele consegue se entranhar na vida cotidiana dos povos subjugados e sobrevive apesar da emancipação das colônias latinoamericanas, asiáticas e africanas nos séculos XIX e XX. O que essa rica produção teórica recente pretende alertar é que, apesar do fim dos colonialismos modernos, 
a colonialidade sobrevive.

O termo colonialidade, segundo o sociólogo peruano Anibal Quijano (2005) faz alusão à invasão do imaginário do outro, ou seja, sua ocidentalização. Mais especificamente, diz respeito a um discurso que se insere no mundo do colonizado, porém também se reproduz no lócus do colonizador. Nesse sentido, conforme o autor, o colonizador destrói o imaginário do outro, invisibilizando-o e subalternizando-o, enquanto reafirma o próprio imaginário. Assim, a colonialidade do poder reprime os modos de produção de conhecimento, os saberes, o mundo simbólico, as crenças, a espiritualidade, as imagens do colonizado e impóe novos. Opera-se, então, a naturalização do imaginário do invasor europeu, a subalternização epistêmica do outro não-europeu e a própria negação e o esquecimento de processos históricos não-europeus.

Nesse sentido, um projeto de educação que se queira emancipador deve estabelecer um amplo e profundo diálogo com os saberes historicamente silenciados, provenientes das experiências dos povos subalternizados pelos processos de colonização na América Latina, sobretudo dos povos indígenas originários dessas terras e dos povos escravizados vindos de África. A ancestralidade, a memória, a oralidade e a ritualidade encarnada nas práticas desenvolvidas por esses povos constituem um acervo de humanidade registrado através de danças, cantos, celebraçóes, religiosidade, formas de se relacionar com a natureza, formas simbólicas de ser e estar no mundo. A esse profundo acervo de humanidade, costumamos dar a denominação de "culturas populares" (Abib, 2005).

A proposta da ACCS "Saberes e Fazeres das Culturas Populares na Educação" é pautada pelo viés da decolonialidade e, em consequência disso, é fundamentalmente interdisciplinar, pois as aproximaçóes teóricas e vivenciais com o universo dos saberes e fazeres das culturas populares tradicionais, implicam numa postura de compreensão desse universo por parte dos sujeitos participantes dessas experiências, a partir de referências dos vários campos do saber, que váo da Educação à Filosofia, dos Estudos Culturais à História, das Artes à Antropologia, das Ciências Naturais à Sociologia, entre outras possibilidades.

Valemo-nos da teoria da multirreferencialidade (Macedo, 2009) como suporte da abordagem utilizada por essa ACCS, a partir de um caminho que, de acordo com Canclini (2008), deve ser transdisciplinar na perspectiva da abertura de cada disciplina às outras. Precisamos de ciências sociais nômades, diz o autor, "capazes de circular entre as escadas que ligam esses pavimentos, redesenhando esses planos através de um caminho que seja ao mesmo tempo incômodo, atraente e valioso" (Canclini, 2008, p. 124). 


\section{Aprendendo com os saberes e fazeres das culturas tradicionais: uma metodologia atravessada pela oralidade e pela experiência}

Essa seção foi escrita a partir do olhar de Lucas Gesteira, co-autor deste artigo e de Rosevânia Machado, colaboradora desta produção. Ambos foram participantes, num primeiro momento como alunos e depois como monitores, da ACCS. A idéia dessa seção é trazer elementos metodológicos da proposta temperados pelo olhar de quem vivenciou as experiências propostas durante alguns semestres. A oralidade na construção do presente artigo se manifesta também dessa forma, a partir dos relatos das experiências vivenciadas por esses ex-estudantes da disciplina em questão.

Assim, antes de continuar, pedimos licença aos mais velhos, aos nossos antepassados, àqueles que já deixaram sua contribuição neste mundo da qual somos herdeiros. Pedimos a permissão ao próprio tempo e também a sua benção para escrever as palavras que se seguem. Por meio dessas, compartilhamos experiências e saberes que foram cuidadosamente construídos através do trabalho de geraçóes e que aqui, respeitosamente, traduzimos na forma de uma metodologia, a qual vamos introduzir conforme a sua proposta: começando pela experiência.

Um violão e um tambor no centro da sala, as cadeiras estão no canto, o professor nos orienta a ficarmos descalços e a nos despedirmos dos aparelhos tecnológicos. Ele se senta no chão e nos convida para formarmos uma roda. Os instrumentos permanecem no centro: um violáo gasto revelando anos de bom uso e um tamborzinho com duas baquetas; o professor tem mais um instrumento que traz mais próximo de si.

O professor faz questão de fitar os olhos de cada um, todos muito curiosos e atentos a cada movimento do nosso facilitador e ele inicia explicando a importância da roda, a importância dele poder ver as pessoas que estão ali e, sobretudo, a importância de que nós, que fazemos parte da roda, possamos trocar olhares e náo focar apenas no professor. Ele nos conta da presença da roda nas diversas culturas de povos e comunidades tradicionais e a energia que uma roda evoca e concentra.

Finalmente nos é apresentado o terceiro instrumento: o maracá; e um novo convite é feito. O maracá, tão utilizado pelos povos originários, composto por uma cabaça com sementes e um cabo de madeira, é símbolo de contato e conexão com a ancestralidade e com os tempos primordiais. Através desse poderoso arquétipo, abrimos um portal de comunicação com o passado e para que possamos falar e aprender sobre os saberes e fazeres tradicionais, precisamos pedir licença, permissão, benção! 
$\mathrm{Na}$ roda de benção somos convidados a fecharmos os olhos, trazermos na memória um ente ou um mestre que ocupa um lugar de sabedoria em nossas vidas e orientados a pedir licença e benção a esse ancestral mentalizado. Dizemos a que curso da UFBA pertencemos, de qual território identitário somos originários e afirmamos o nosso nome na roda com a força do som do maracá. Esse mesmo gesto é repetido por todos enquanto o maracá é passado de mão em mão na roda.

Após passarmos pelo encantamento na roda de benção e apresentação, vem a vivência. Assim, todos de pé, ainda em círculo, somos guiados pelo professor no universo dos cantos e danças tradicionais. Começamos pela ciranda, primeiro aprendendo lentamente seu ritmo e o seu passo, através do som do tambor. Após um contato inicial com a ciranda, aprendemos com mais cuidado seus versos e quando os repetimos, o fazemos cantando todos juntos, o que aumenta ainda mais a energia da ciranda e aprofunda a conexão de todos que nela estão envolvidos. $\mathrm{O}$ professor diz que nas culturas populares não existe muita separação entre o trabalho, a festa e a religião. Apresenta os nomes das principais referências da ciranda em Pernambuco como o Mestre Baracho e a Lia de Itamaracá e assim, por meio das histórias, da música e da dança, vão se estabelecendo, sutilmente, conexôes com as comunidades tradicionais, seus saberes e fazeres.

Numa outra vivência, ao estudar sobre a capoeira, a proposta se inicia com todos se deslocando imaginariamente à África, numa grande floresta, onde todos incorporam algum animal e começam a se movimentar como ele. Ao som do berimbau tocado pelo professor, sentimos o ritmo do corpo de cada um e olhando nos olhos uns dos outros, vivenciamos o movimento dos animais que inspiraram os movimentos dessa dança e luta afro-brasileira que é a capoeira. A partir daí praticávamos os movimentos que o professor aprendera com Mestre João Pequeno de Pastinha e, nesse movimento, ouvíamos também suas histórias, a simbologia dos golpes, seus mistérios, sobre a ética e a filosofia próprias da capoeira e sobretudo a sua forte simbologia enquanto luta pela liberdade em tempos de escravidão.

Tão importante quanto estudar as tradiçóes dos povos negros, como a ciranda e a capoeira, é o estudo e a vivência das tradiçóes dos povos originários. Assim, em um outro momento, de posse do seu maracá, o professor nos fala sobre esses povos, suas lutas, a violência que sofreram e continuam a sofrer, a diversidade de etnias e línguas indígenas presentes no Brasil, a luta pela terra e pelo direito à sua língua e à sua cultura. Diz também que nossos povos originários possuem danças rituais muito antigas, que em muitas comunidades são denominadas de "toré", ritual pelo qual eles se conectam uns aos outros e ao propósito que os movimenta. Primeiro, aprendemos a marcação da dança, batendo o pé no chão, acompanhando o som do maracá. Sáo cantos simples, com poucos versos, no idioma original, cujo côro intuitivamente aprendemos a responder. Existem 
inúmeros torés e cada um possui uma finalidade específica, com uma mensagem própria para cada povo indígena e para cada ocasião.

Num outro momento, os alunos são levados a um clima de aconchego através de cantigas de roda e cantigas de ninar, frequentemente presentes no imaginário de tantas pessoas associadas a uma memória afetiva ligada à infância. Essas cantigas possuem um lugar estratégico que permite a cada um se recolher no interior de si mesmo. Assim, somos preparados para o momento de, enfim, conversar sobre nossas experiências.

$\mathrm{Na}$ semana anterior o professor havia pedido para que os alunos pesquisassem sobre sua árvore genealógica, ouvissem as histórias de seus mais velhos, procurassem seus pais, avós, tios, parentes mais idosos em busca dessas informaçóes e as trouxessem para compartilhar no encontro seguinte. Assim, gentilmente, somos convidados a contar uma história relativa aos nossos ancestrais, à nossa família.

A metodologia utilizada nesta ACCS, portanto, é do tipo que parte da experiência e da vivência para construir o conhecimento, que num momento posterior atinge o plano teórico. Esse é um caminho metodológico que, no Brasil, possui grande força, sobretudo nas práticas educativas que visam lidar com o povo e com os saberes populares e que encontra em Paulo Freire (2004) um referencial expressivo do ponto de vista pedagógico. Entretanto, ainda que nesta ACCS valorize-se profundamente os saberes da oralidade, também são realizadas atividades entre os estudantes que buscam trabalhar com conceitos teóricos, uma vez que eles já estejam sensibilizados pela vivência. Assim, também são utilizadas técnicas educativas mais comuns ao meio acadêmico, embora numa proporção menor do que em outras disciplinas, como leitura e discussão de textos teóricos que dialoguem sobre os temas propostos, ou a exibição de documentários em sala de aula. Dessa forma, a metodologia desenvolvida nesta ACCS valoriza tanto o saber prático e vivencial trazido pela oralidade, quanto a reflexão teórica, buscando uma complementação entre ambos.

As atividades são organizadas a cada semestre segundo a necessidade e as características de cada grupo de estudantes que se forma e de cada contexto, comunidade ou mestre(a) que seráo temas da disciplina durante o semestre. Assim se constitui o caminho metodológico dessa disciplina que vem sendo trilhado continuamente ao longo de todas as turmas que por ela passaram, assim como também a partir da própria trajetória de décadas do professor como aprendiz das culturas populares e suas relaçóes com as mestras e com os mestres, cultivadas nesse percurso.

A metodologia é, portanto, construída cotidianamente, inspirada nos processos de transmissáo de conhecimento e aprendizagem presentes no universo das culturas populares de forma geral e também em outras experiências já 
consolidadas como o Encontro de Saberes da $\mathrm{UnB}^{1}$, a Pedagogia Griồ ${ }^{2}$, além de outras experiências vivenciadas nas comunidades por nós visitadas durante as viagens previstas como atividade curricular da disciplina.

Entre as expressóes, brincadeiras, danças e ritmos das culturas populares que constituem os saberes e fazeres empregados nessa metodologia citamos: capoeira, ciranda, côco, cacuriá, samba de roda, samba urbano, chorinho, caroço, torés, danças circulares, jongo, catira, baião, congado, marujadas, zambiapunga, danças dos orixás, entre outras.

É fundamental aqui destacar o lugar das mestras e dos mestres das culturas populares nesta ACCS. Esses são os verdadeiros guardióes dos saberes tradicionais e da oralidade e o diálogo com eles constitui uma peça essencial da metodologia aqui empregada, possibilitando o reconhecimento e a interação direta com essas referências tão importantes, fonte dos saberes e fazeres estudados na disciplina. Entre os mestres e as mestras das culturas populares que já passaram por esta ACCS ou foram visitados por ela, citamos: Bule-Bule, Nelito do Pandeiro, Vovó Cici, Dona Gegê, João do Boi, Mestre Primeiro, Zeca Afonso, Dona Nicinha, Dona Dalva Damiana, Walmir Lima, Milton Primo, Mestre Zoinho, Ganhadeiras de Itapuã, Mestre Reginaldo, Mestre Felipe Santiago, Mestre Pedreira, Dona Cabocla, Dona Biu, Dona Joca, Taquari Pataxó, Mestre Roxinho, Mestra Ritinha, Mestra Nani de João Pequeno, Mestra Jararaca, Taata Luongomina, Mestre Cobra Mansa, entre vários outros.

É por meio dos encontros com os mestres e mestras que se realizam alguns dos principais objetivos desta disciplina. Primeiro, é fundamental que o encontro com os mestres se dê sempre após a turma já ter sido devidamente apresentada à expressão da cultura popular da qual aquela mestra ou aquele mestre se ocupa da transmissão. Apenas após ouvir, vivenciar e dialogar suficientemente sobre cada expressão cultural e sobre a importância dos mestres que são seus guardióes, criase uma sensibilização e um espaço propício para que haja esse encontro.

Foi após uma série de aulas de preparação sobre capoeira, por exemplo, que conhecemos a inesquecível Mestra Ritinha de João Pequeno (1967-2018). Mestra Ritinha, falecida precocemente, era uma mulher forte, com muita fibra e que nos presenteou com uma aula seguindo à risca o método do Mestre João Pequeno.

1 O Encontro dos Saberes é uma experiência pioneira coordenada pelo prof. José Jorge de Carvalho, desenvolvida pela Universidade de Brasília (UnB) desde o ano de 2008, que busca aproximar os saberes acadêmicos dos saberes tradicionais no âmbito da universidade.

2 A Pedagogia Griô é uma pedagogia criada pela educadora Lillian Pacheco a partir da sua prática pedagógica na Associação Grãos de Luz e Griô, em Lençóis (BA). A vivência, a oralidade e a corporeidade são referências do processo de elaboração do conhecimento; e os griôs e mestres protagonistas na educação da comunidade. 
Após a vivência com a Mestra Ritinha, que foi um treino de capoeira angola da mais alta classe, fizemos então uma roda de diálogos na qual a Mestra compartilhou um pouco do seu saber e da sua história na academia de João Pequeno. Entre as tantas coisas que ela falou, uma que ficou gravada pela turma foi a de ter sido ela a única mulher do seu tempo que permaneceu na academia. Dizia ela "as outras todas vinham e passavam, só eu ficava”. Quando foi questionada se já havia sofrido machismo na capoeira, ela disse categoricamente que não. Afirmava saber que existe machismo na capoeira e bastante, mas dizia nunca ter sofrido, porque nunca permitiu que a discriminassem pelo seu gênero.

Esses momentos de encontros com os mestres e mestras são revisitados posteriormente em outras aulas, quando são aprofundados debates e reflexóes sobre as temáticas, sentimentos e percepçóes que afloraram dessas vivências, buscando construir um olhar crítico acerca de questóes atuais como: machismo, racismo, discriminação, desigualdades, violências, exploração, direitos, liberdades, tolerância, diversidade, entre tantas outras.

Um aspecto bastante importante dessa ACCS é que está previsto no plano pedagógico da disciplina uma ou duas viagens por semestre para territórios e comunidades tradicionais, através do apoio da Pró-Reitoria de Extensão da UFBA no aspecto financeiro. A turma é preparada através de uma série de vivências, estudos e informaçôes sobre o território, as comunidades e as manifestaçóes da cultura popular que serão visitadas. Busca-se com isso aguçar a sensibilidade dos estudantes para perceber os sinais e ensinamentos sutis que as comunidades tradicionais nos transmitem.

Entre as idas rotineiras a campo, fomos ao bairro de Itapuâ, em Salvador (BA), onde visitamos a Casa da Música, um importante centro cultural local, no qual somos apresentados a Seu Regi, grande sambista e compositor do bairro, que através das suas composiçóes nos conta sua história, assim como as tantas histórias de Itapuá. Seu Regi nos guia pela comunidade versando músicas de sua autoria e improvisando cantorias sobre as belezas do seu bairro, louvaçóes a moradores mais antigos, cantando a história de ruas e praças e nos encantando durante a caminhada.

Visitamos a matriarca de Itapuá, Dona Cabocla (1915-2018) - uma negra centenária que, a pesar do corpo aparentemente cansado, nos recebeu dançando e cantando: "Suará êê êê, suará! Suará nas mãos de Deus, Suará!", enquanto revolvia suas memórias nos contando histórias dos tempos antigos do bairro.

Em seguida, na mesma rua um pouco mais acima, nós visitamos a sede das Ganhadeiras de Itapuã - importante grupo cultural formado pelas antigas lavadeiras da Lagoa do Abaeté - e somos recebidos por alguma delas. O cheiro do feijāo já perfuma a rua quando chegamos para conversar com essas admiráveis 
mulheres. Elas nos contam seus relatos, suas histórias de luta no tempo de lavar as "roupas de ganho" na lagoa e também quando percorriam até $30 \mathrm{~km}$ à pé até o centro da cidade, carregando um grande balaio, onde vendiam beiju, doce de tamarindo, banana e de goiaba, além das cocadas e bolinhos de estudante.

Por vezes é difícil para elas conterem as lágrimas diante de suas dolorosas lembranças, mas elas trazem também boas novas. Reconhecidas através das suas músicas, as Ganhadeiras de Itapuã hoje ganham prêmios e viajam o Brasil fazendo shows e dando palestras. Encerramos essa visita com o luxo de ouvi-las cantar e agradecidos pelo saboroso feijão oferecido.

Assim como Itapuâ, muitas outras comunidades tradicionais foram visitadas ao longo das diversas turmas dessa ACCS. Listamos alguns dos principais lugares. Em Salvador: Forte da Capoeira, Fundação Pierre Verger, Pelourinho, Comunidade do Alto das Pombas. No Recôncavo Baiano: Santo Amaro, Cachoeira, Iguape, São Braz, São Francisco do Conde, Maragogipe, Acupe, Saubara. No Baixo Sul: Valença, Nilo Peçanha, Camamu, Ilha Grande, Museu da Costa do Dendê. Também foram visitados o Quilombo Tapuia, o Quilombo Dom João, e o Kilombo Tenonde.

A cada viagem busca-se sempre oferecer algo em retribuição pelo acolhimento a cada comunidade que recebe esta ACCS, seja através de pequenos cachês destinados aos mestres e mestras (recursos previstos no edital da ACCS), seja através de bens simbólicos, como a oferta de uma canção, uma dança, um desenho, uma brincadeira ensinada, entre outras.

Por fim, uma prática fundamental que está inserida na metodologia desta ACCS é a produção partilhada, que consiste na confecção, por parte dos estudantes, de um produto original e que se torne significante do processo vivido por cada aluno nesta disciplina. A produçáo partilhada pode ser de diversos tipos, tais como desenhos, relatos ou poesias. Mas a mais utilizada, sob a orientação do professor, consiste na criação, pelos alunos, de curtas-documentários sobre alguma manifestação da cultura popular, ou sobre algum mestre ou mestra que participaram dos encontros, ou ainda sobre algum outro membro de sua comunidade, de sua regiāo. Essa atividade constitui também instrumento de avaliação dos estudantes.

Entre os curta-documentários produzidos pelos estudantes, temos por exemplo, filmes que falam sobre as rendeiras, as benzedeiras, as rezadeiras, sobre o candomblé, a capoeira, o maracatu, as festas populares, assim como seus respectivos mestres e mestras, ou grupos que se ocupam da preservaçáo e da difusão desses saberes e fazeres tradicionais. A ACCS possui um canal no YouTube dedicado à veiculação dessa produção, que já conta com um acervo de 45 vídeos (curtadocumentários), além de páginas nas diversas redes sociais para compartilhar e divulgar suas açóes. 


\section{Diálogo entre saberes: estudantes universitários descobrindo e experienciando saberes tradicionais}

Como forma de acrescentar elementos para essa reflexão, trazemos nesta seção relatos de estudantes que participaram da ACCS entre os anos de 2015 e 2019, provenientes dos mais diferentes cursos de graduação e pós-graduação da UFBA, e também dos programas de intercâmbio com outras universidades brasileiras e estrangeiras, sobre como as experiências vivenciadas contribuíram com seu processo de formação acadêmica e que tipo de transformaçóes eles percebiam no seu processo de formação humana de forma geral. Foram a partir dos relatórios finais da disciplina solicitado aos alunos a cada semestre, que retiramos alguns dos trechos a seguir.

Nos aspectos políticos podemos trazer algumas reflexóes importantes dos estudantes, tais como:

Nestes tempos, que as forças mais conservadoras e oligárquicas retomam o poder nos países latino-americanos com uma estratégia que desfoca e elimina o diferente, aquele que pensa e aquele que não tem; aulas e propostas pedagógicas como estas são uma semente em nome da resistência. (Daniel Restrepo González, 2018).

O que a ACCS me trouxe é a importância política de propagar a cultura oral, táo rica para nós, e que pode se perder no meio desse projeto político massivo de apagamento, e desvalorização da nossa história. Sinto, a partir do que vivi nesses seis meses que o resgate disso se faz no presente, é aqui que nos firmamos, de mãos dadas, numa ciranda, com o nosso passado. (Ana Carolina Bastos dos Santos, 2018).

Sobre os aspectos relacionados à ancestralidade e identidade, destacamos alguns trechos de depoimentos, como:

De fato me senti progressivamente tomado por um sentimento, que ainda hoje segue vivo e forte em meu peito: o sentimento do amor pelo meu povo negro, caboclo, indígena, quilombola, pelas suas tradiçóes e pelas suas culturas. Ainda que eu não seja racialmente pertencente a nenhum desses povos, me sinto a eles ligados, porque reconheço que partilhamos elementos culturais comuns, quando reverenciamos nossos ancestrais e a eles nos consultamos antes de dar os passos importantes que iráo traçar o nosso futuro. (Lucas Gesteira, 2017). 
O ensino se faz pelas descobertas feitas e valorizadas fora dos muros da universidade e da academia. Por exemplo, os compartilhamentos que fizemos na aula sobre as nossas histórias familiares e a nossa genealogia valorizou nossas memorias familiares e nos trouxe a falar das nossas raízes com os idosos das nossas famílias. (Léa Bouhelier-Gautreau, 2017).

As vivências relatadas e saberes têm uma grande base emocional. Pois a cada nova apresentação ou chegada dessas "mestras" com seu conhecimento e conteúdo, percebia o quanto de amor, zelo, respeito e carinho recebia também. Suas lutas, sonhos, desejos, realizaçóes, dores, perdas também serviu de ensinamentos. E recebo logo de início uma atividade onde tenho que montar minha árvore genealógica e logo sou inundada por emoçóes diversas. (Amélia Braga Silva, 2018).

A memória, o que é passado de "boca em boca", o cuidado, a ancestralidade, a fé do poder de cura das folhas e da natureza, tudo isso está relacionado à cultura popular. Ee é algo que vem se perdendo, com a nova era dos turbilhóes de informaçóes, não nos damos conta que açóes simples como sentar com nossos avós, com nossos mais velhos, ouvir suas histórias são momentos extremamente importantes para eles e para nós. (Beatriz Pinho Conceição, 2018).

A disciplina fez com que eu me sentisse mais próxima e mais conectada a minha própria história e, sobretudo, a história coletiva do povo brasileiro e sua constituição. Enquanto educadora em formação, considero a disciplina como decisiva nos rumos que a minha atuação enquanto professora toma daqui pra frente. (Carolina de Lima Teles, 2017).

Realmente, os relatos que escutei, muitas vezes com lágrimas escorrendo nas faces das pessoas, foram muito fortes e ricos. A dinâmica possibilita uma circulação de energia, uma vivência que lembra os rituais sagrados das tribos. Quando as pessoas se dão conta já estão colocando nas rodas histórias que nunca haviam partilhado com outras pessoas. Isso é muito forte! (Maurício Brasil, 2018).

Minha relação com a cultura popular sempre foi distante achava que era coisa de velho e chata, odiava samba e qualquer coisa relacionada. Logo na primeira aula já levei um baque de como eu deveria valorizar meus ancestrais, meus avós e até mesmo minha família. (Estephany Conceição dos Santos, 2018). 
Essa disciplina é um território de afeto. Quando me matriculei nessa eletiva busquei uma boia salva-vidas nesse mar que é a universidade e encontrei essa disciplina, festiva, vivencial e corpórea que me colocou em contato com mestres protagonistas em suas comunidades, manifestaçóes culturais distintas e me pôs diante da minha raiz ancestral. Aprendi uma nova forma de ocupar a sala de aula, retomando a minha identidade e a minha fala nesse ambiente. (Rosevânia Machado, 2017).

Tratando das relaçóes entre os saberes acadêmicos e populares, trazemos outros trechos de depoimentos que julgamos interessantes:

Uma das grandes defasagens do academicismo que foi superado nesta disciplina é a práxis. Nesta ACCS, tivemos a possibilidade de imergir no berço da cultura popular: comunidades em cidades diferentes que vivem o popular no seu dia a dia. (Pedro Canuto Pinto Oliveira, 2017).

A oralidade foi o combustível para as aulas, confesso que para mim o ato de anotar é algo muito presente em minha vida. E conhecer uma outra forma de aprender a partir da oralidade, reflexão, pratica e diálogo é tão importante quanto. (Janeide Silva Oliveira, 2018).

A disciplina nos proporcionou o contato direto com populaçóes consideradas resistentes, que preservam as suas singularidades. Mas, ao mesmo tempo em que são únicas, possuem certas proximidades entre elas, com um grande número de conhecimentos presentes nesses lugares, onde sempre tentaram oculta-los e silencia-los ao longo do tempo. (Mahal Machado, 2018).

Honestamente, foi a maneira mais bonita que tive de me apresentar e conhecer meus colegas. É muito importante entender os fatos do presente, conhecer o passado, isto é, nossa história, para que conhecer as pessoas seja exatamente o mesmo. (Andrea Espinosa Prieto, 2018).

'Não é o analgésico, é a cura', essa frase surgiu em uma das nossas conversas pós prática e me marcou bastante como o real sentido do componente, apesar de ser algo tão claro, mas talvez pelo fato de ter conseguido sintetizar todo o propósito em uma frase tão curta. (Gilmar Leal Silva Junior, 2017).

Os saberes e fazeres da cultura popular exigem que o corpo esteja presente. A expressão corporal, seja no samba, no canto, na construção da viola machete, no toque do tambor, na mariscagem, no alimento e no ato de comer, todas as práticas evocam as forças ancestrais. (Luzia Elisa Oliveira Santos, 2017). 
O ritual de começar a aula pedindo a bênção aos nossos ancestrais me lembra que eu acendo de pessoas importante, de significativas contribuiçóes para o que eu sou hoje. Isso aflora a gratidáo. (Eduardo Barreto Andrade, 2018).

Essa disciplina me ajudou desmitificar muitas coisas que eu já estava em processo, minha família é do interior de Ilhéus e moram em uma roça, a religião de lá é a pentecostal então cresci com diversos preconceitos. (Naira Lise Santos de Aquino, 2017).

Sobre as viagens aos territórios de origem de mestres e manifestações tradicionais que fazemos todos os semestres, mais alguns depoimentos importantes:

As viagens que fizemos aos territórios de culturas tradicionais para conhecermos os mestres e mestras foram como viagens para dentro de nós mesmos. Pudemos saber mais sobre nossa identidade, conhecer quem somos nós de verdade, nossa origem, as memórias que nos constroem como pessoas. (Leila Abricó, 2017).

O Recôncavo é um grande manancial de cultura. Viajar pra esse território ancestral foi uma das experiências mais marcantes de toda a minha formação. Ter contato com mestres todos anciãos e anciãs que guardam uma sabedoria infinita, é uma experiência que nos transforma profundamente. (Carlos Fogaça, 2018).

As viagens têm me ajudado a aprender de diferentes formas, experimentar o conhecimento através de outros métodos como a "oitiva" e a "oralidade", ao me tirar do lugar comum de acadêmico e me colocar nos locais de vivência. (Alison Conceição Brito, 2017).

Esses lugares que visitamos me despertaram o sentido de resistência em relação a aspectos do passado onde minha descendência negra sofreu e cujas consequências ainda reverberam atualmente; e a importância de trazer ao mental, aos olhos, aos ouvidos, à pele, ao corpo os conhecimentos dos meus antepassados. (Eliane Ferreira da Silva, 2018).

Nessa viagem eu experimentei uma sensação de integração e desafio. Misto que pode ser utilizado como síntese da viagem. Estar táo próximo da terra e de tanto mato, rio perto, banho fácil, de noite, lua cheia, vagalume. Ar fresco de vida perto, verde perto.... A atentar com mais cuidado para o que minha mãe, tias, vizinhas... relatam sobre suas andanças e vivências sobre um 
sertão que não conheci e me deixar afetar sobre esses saberes para entender se de que modo eles podem me ajudar a construir outras possibilidades para a terra de onde eu vim mas não deixei e para as outras que ainda penso em conhecer. (Francisco Soares Sena, 2017).

O quilombo para além de ser um espaço que resgata os ensinamentos da cultura afro-brasileira, no âmbito cultural, social, natural, ou seja no cuidado com a floresta, a terra, as aguas, é uma fonte de fortalecimento e resistência. (Ione Jesus Costa, 2017).

Volto para Salvador pensando no que estava fazendo esse tempo todo, inclusive na academia; me pergunto a que lógica eu quero seguir e em nome de quem ou do quê eu quero falar. Já sei que quero falar em nome de mim mesma, Julia, dos meus e em nome do que é por mim experienciado. Nasci em um país, numa cultura, numa história e me parece muita falta de responsabilidade não saber de todas essas coisas que ecoam, ou deveriam ecoar, de mim. (Julia Campos Rezende, 2017).

Seu Brasilino não estudou numa universidade. Dona Maria não fez mestrado em azeite de dendê. Na escola técnica não ensinaram Adalício a fazer farinha de mandioca. A escola de medicina de seu Leonel foi a prática. Capoeira não se ensina em todos os colégios. Pretinha é Phd em farinhada. Estas pessoas são simples, mas são ricas. E é aí que a gente toma um tapa de realidade. A riqueza deles não é mensurada pelo tanto de dinheiro que têm na conta. Não é medida pela marca da roupa, pelo carro do ano nem pelo apartamento espaçoso. A beleza no olhar, a despreocupação com o horário, o riso fácil, a conversa brejeira e carinhosa. Essa é a riqueza daquele povo. (Marcos de Oliveira Lopes, 2017).

\section{Tecendo considerações sobre a experiência}

Narrar uma experiência com toda a potência que dela emana, descrever em palavras os afetos nela envolvidos, buscar racionalizar as percepçóes e ensinamentos que dela afloram ao tentar transformá-la num texto acadêmico, é uma tarefa das mais difíceis, diríamos mais, um desafio quase intransponível.

Por isso o objetivo maior deste artigo não foi apenas trazer elementos teóricometodológicos que possam fundamentar uma proposta de educação para o ensino superior que valorize os saberes e fazeres tradicionais por meio da experiência e da oralidade, e que possam servir em última análise, também como inspiração 
para outras experiências educativas em outros níveis de ensino e para outras modalidades de educaçáo formal e não-formal em qualquer parte do Brasil. Para além desses objetivos, este artigo buscou criar um canal de diálogo com aqueles e aquelas que buscam construir propostas de educação baseadas nas experiências mais profundas provenientes da trajetória do povo sofrido e marginalizado no nosso país, que soube resistir por séculos à violência física e simbólica a que foi submetido, sempre com muita criatividade e alegria, celebrando, cantando, dançando e fazendo festa.

Esse talvez seja o maior ensinamento que os processos educativos baseados nas culturas populares e seus saberes e fazeres tradicionais nos proporcionam. Os valores e princípios presentes nos universos das culturas populares, em que pese as contradiçóes que engendram, são antes de mais nada inspiração para uma educação libertadora, pois baseada na valorização da memória, da ancestralidade, da identidade, das estratégias de resistência e das lutas do nosso povo. Por isso decolonial e por isso mais humana.

Essa forma de compreender as relaçóes entre os diferentes saberes no âmbito da academia nos parece ser a mensagem que este artigo busca espalhar pelos quatro cantos, através do vento forte que emana das culturas populares, que também é brisa leve soprada pelo hálito dos nossos ancestrais.

\section{Referências}

ABIB, Pedro Rodolpho Jungers. Capoeira Angola: cultura popular e o jogo dos saberes na roda. Campinas: CMU-Unicamp; Salvador: EDUFBA, 2005.

. Cultura Popular e Contemporaneidade. Patrimônio e Memória, São Paulo, v. 11, n. 2, p. 102-122, jul./dez. 2015.

. Culturas Populares, Educação e Descolonização. Revista Educação em Questão, Natal, v. 57, n. 54, out./dez. 2019.

ALBERTI, Verena. Ouvir contar: textos em História Oral. Rio de Janeiro: FGV, 2004

BHABHA, Homi K. O Local da Cultura. Tradução Myriam Ávila, Eliana Lourenço de Lima reis, Gláucia Renate gonçalves.. Belo Horizonte: Editora UFMG, 2008.

CANCLINI, Nestor Garcia. Culturas Hibridas. São Paulo: Edusp, 2008.

CANDAU, Vera Maria Ferrão; OLIVEIRA, Luiz Fernandes. Pedagogia decolonial e educação antirracista e intercultural no Brasil. Educação em Revista, Belo Horizonte, v. 26, n. 1, p. 15-40, abr. 2010. 
CHAUÍ, Marilena. Conformismo e Resistência: aspectos da cultura popular no Brasil. 4. ed. São Paulo: Brasiliense, 1989.

FREIRE, Paulo. Pedagogia do Oprimido. 38. ed. Rio de Janeiro: Paz e Terra, 2004.

HALL, Stuart. Da diáspora: identidades e mediaçóes culturais. Belo Horizonte: Humanitas, 2009.

KRENAK, Ailton. A potência do sujeito coletivo. [Entrevista concedida a] Jailson de Souza e Silva. Blog Combate Racismo Ambiental, 2 jun. 2018. Disponível em: <https:// racismoambiental.net.br/2018/06/02/ailton-krenak-a-potencia-do-sujeito-coletivoparte-i/>. Acesso em: 12 jun. 2020.

MACEDO, Roberto Sidnei; GALEFFI, Dante; PIMENTEL, Álamo. Um rigor outro: sobre a qualidade na pesquisa qualitativa - educaçáo e ciências antropossociais. Salvador: EDUFBA, 2009.

MALDONADO-TORRES, Nelson. Sobre la colonialidad del ser: contribuciones al desarrollo de un concepto. In: CASTRO-GÓMEZ, Santiago; GROSFOGUEL, Ramon (Org.) El giro decolonial: reflexiones para una diversidad epistémica más allá del capitalismo global. Bogotá: Siglo del Hombre Editores; Universidad Central, Instituto de Estudios Sociales Contemporáneos y Pontificia Universidad Javeriana, Instituto Pensar, 2007. p. 127-167.

QUIJANO, Anibal. Colonialidade do poder, eurocentrismo e América Latina. In: LANDER, Edgardo (Org.). A colonialidade do saber: eurocentrismo e ciências sociais Perspectivas latino-americanas. Buenos Aires: CLACSO, 2005. p. 227-278.

WALSH, Catherine. Pensamiento critico y matriz (de)colonial: Reflexiones latinoamericanas. Quito: Ediciones Abya-Yala, 2005.

\section{Fontes orais}

ABRICÓ, Leila [24 anos]. [jul 2017]. Entrevistador: Pedro Rodolpho Jungers Abib. Salvador, BA, jul. 2017.

ANDRADE, Eduardo Barreto [24 anos]. [jul 2018]. Entrevistador: Pedro Rodolpho Jungers Abib. Salvador, BA, jul. 2018.

AQUINO, Naira Lise Santos de [25 anos]. [jul 2017]. Entrevistador: Pedro Rodolpho Jungers Abib. Salvador, BA, jul. 2017.

BOUHELIER-GAUTREAU, Léa Chantal Stéphanie [21 anos]. [jul 2018]. Entrevistador: 
Pedro Rodolpho Jungers Abib. Salvador, BA, jul. 2018.

BRASIL, Maurício [43 anos.] [jul 2018]. Entrevistador: Pedro Rodolpho Jungers Abib. Salvador, BA, jul. 2018.

BRITO, Alison Conceição [25 anos]. [jul 2017]. Entrevistador: Pedro Rodolpho Jungers Abib. Salvador, BA, jul. 2017.

CONCEIÇÃO, Beatriz Pinho [21 anos]. [jul 2018]. Entrevistador: Pedro Rodolpho Jungers Abib. Salvador, BA, jul. 2018.

COSTA, Ione Jesus [31 anos]. [jul 2017]. Entrevistador: Pedro Rodolpho Jungers Abib. Salvador, BA, jul. 2017.

FOGAÇA, Carlos [21 anos]. [jul 2018]. Entrevistador: Pedro Rodolpho Jungers Abib. Salvador, BA, jul. 2018.

GESTEIRA, Lucas [23 anos]. [jul 2017]. Entrevistador: Pedro Rodolpho Jungers Abib. Salvador, BA, jul. 2017.

GONZÁLEZ, Daniel Restrepo [23 anos]. [jul 2018] Entrevistador: Pedro Rodolpho Jungers Abib. Salvador, BA, jul. 2018.

LOPES, Marcos de Oliveira [28 anos]. [jul. 2017]. Entrevistador: Pedro Rodolpho Jungers Abib. Salvador, BA, jul. 2017.

MACHADO, Mahal [21 anos]. [jul 2018]. Entrevistador: Pedro Rodolpho Jungers Abib. Salvador, BA, jul. 2018.

MACHADO, Rosevânia [23 anos]. [jul 2017]. Entrevistador: Pedro Rodolpho Jungers Abib. Salvador, BA, jul. 2017.

OLIVEIRA, Janeide Silva [20 anos]. [jul 2018]. Entrevistador: Pedro Rodolpho Jungers Abib. Salvador, BA, jul. 2018.

OLIVEIRA, Pedro Canuto Pinto [25 anos]. [jul 2017]. Entrevistador: Pedro Rodolpho Jungers Abib. Salvador, BA, jul. 2017.

PRIETO, Andrea Espinosa [23 anos]. [jul 2018]. Entrevistador: Pedro Rodolpho Jungers Abib. Salvador, BA, jul. 2018.

REZENDE, Julia Campos [21 anos]. [jul. 2017]. Entrevistador: Pedro Rodolpho Jungers Abib. Salvador, BA, jul. 2017.

SANTOS, Ana Carolina Bastos dos [21 anos]. [jul 2018] Entrevistador: Pedro Rodolpho Jungers Abib. Salvador, BA, jul. 2018. 
SANTOS, Estephany Conceição dos [22anos]. [jul 2018]. Entrevistador: Pedro Rodolpho Jungers Abib. Salvador, BA, jul. 2018.

SANTOS, Luzia Elisa Oliveira [20 anos]. [jul 2017]. Entrevistador: Pedro Rodolpho Jungers Abib. Salvador, BA, jul. 2017.

SENA, Francisco Soares [22 anos]. [jul 2017]. Entrevistador: Pedro Rodolpho Jungers Abib. Salvador, BA, jul. 2017.

SILVA, Amélia Braga [21 anos]. [jul 2018]. Entrevistador: Pedro Rodolpho Jungers Abib. Salvador, BA, jul. 2018.

SILVA, Eliane Ferreira da [21 anos]. [jul 2018] . Entrevistador: Pedro Rodolpho Jungers Abib. Salvador, BA, jul. 2018.

SILVA JUNIOR, Gilmar Leal [21 anos]. [jul 2017]. Entrevistador: Pedro Rodolpho Jungers Abib. Salvador, BA, jul. 2017.

TELES, Carolina de Lima [24 anos]. [jul 2017]. Entrevistador: Pedro Rodolpho Jungers Abib. Salvador, BA, jul. 2017.

Resumo: Esse artigo busca reunir elementos para uma reflexão sobre práticas educacionais baseadas na experiência e na oralidade, que aproximam a formação acadêmica de cursos de graduação e pós graduação da prática e o conhecimento de comunidades tradicionais vinculadas às ancestralidades africanas e indígenas, como formas de reconhecimento e valorização desses saberes e práticas num processo de formaçáo humana no ensino superior de nosso país.

Palavras-chave: Culturas Populares. Educação. Universidade. Pensamento Decolonial.

\section{Popular cultures at the university: a decolonial education proposal}

Abstract: This article seeks to collect elements for a reflection about educational practices based on experience and orality, which bring the academic training of graduation and post-graduation courses closer to the practice and the knowledge of traditional communities linked to african and indigenous ancestry, as means of recognition and valorization of this knowledge and practices in a process of human training in the higher education of our country.

Keywords: Popular culture. Education. University. Decolonial thinking.

Recebido em 27/03/2020

Aprovado em 18/05/2020 